\title{
Claves para la definición de un Estatuto del directivo público profesional
}

\section{Professional civil service manager: legal definition keys}

\author{
Juan Antonio Carrillo Donaire \\ Universidad de Sevilla (España) \\ ORCID: https://orcid.org/0000-0002-3174-5254 \\ donaire@us.es
}

\begin{abstract}
NOTA BIOGRÁFICA
Acreditado a Catedrático de Derecho Administrativo. Profesor asociado de Derecho Administrativo en la Universidad de Sevilla y abogado. Consejero electivo del Consejo Consultivo de Andalucía. Sus principales líneas de investigación son la seguridad y la calidad industrial, riesgos del progreso, el Derecho patrimonial público, la contratación administrativa, la expropiación forzosa y la responsabilidad patrimonial de las Administraciones Públicas.
\end{abstract}

\section{RESUMEN}

Este trabajo analiza la figura del directivo público profesional, escasamente desarrollada en España a partir de las previsiones del Estatuto Básico del empleado público, exponiendo la incipiente regulación de la figura en algunas Comunidades Autónomas y en el Derecho Comparado. Asimismo desbroza propositivamente las claves de conformación de un Estatuto del directivo profesional a partir de las recientes recomendaciones de la OCDE, de las que nuestro país está aún bastante alejado.

\section{PALABRAS CLAVE}

Empleo público; directivo público; Estatuto del directivo público profesional.

\begin{abstract}
This paper analyzes the figure of the professional civil service manager, barely developed in Spain yet, exposing the incipient regulation of the figure in some Autonomous Communities and in Comparative Law. It also purpose the keys to performance a Civil service management Code based on the recent OECD recommendations, from which Spain is still quite far away.
\end{abstract}

\section{KEYWORDS}

Civil service; Senior Civil Service; Civil Service Management Code.

\section{SUMARIO}

1. LA ESCASA Y DEFICIENTE REGULACIÓN DE LA FIGURA DEL DIRECTIVO PÚBLICO PROFESIONAL EN LA LEGISLACIÓN ESTATAL. LA CONCEPCIÓN DE LA FUNCIÓN DIRECTIVA ENTRE LA POLITIZACIÓN Y LA FUNCIONARIZACIÓN. 2. AVANCES DEL LEGISLADOR AUTONÓMICO A PARTIR DE LAS PREVISIONES BÁSICAS DEL EBEP Y ALGUNAS EXPERIENCIAS RELEVANTES DE DERECHO COMPARADO. a) EL «SENIOR CIVIL SERVICE» BRITÁNICO. b) EL SISTEMA FRANCÉS DE LOS «EMPLOIS DE DIRECTION». c) EL EXITOSO MODELO DE LA CRESAP PORTUGUESA. d) LAS 
EXPERIENCIAS DE ARGENTINA, CHILE Y PERÚ 3. RASGOS DEFINIDORES DEL ESTATUTO DEL DIRECTIVO PÚBLICO A PARTIR DE LAS RECOMENDACIONES DE LA OCDE: CLAVES PARA UNA PROPUESTA. 4. CONCLUSIONES.

\section{LA ESCASA Y DEFICIENTE REGULACIÓN DE LA FIGURA DEL DIRECTIVO PÚBLICO PROFESIONAL EN LA LEGISLACIÓN ESTATAL. LA CONCEPCIÓN DE LA FUNCIÓN DIRECTIVA ENTRE LA POLITIZACIÓN Y LA FUNCIONARIZACIÓN}

Hace aproximadamente un siglo, en el Capítulo final de su Economía y Sociedad, dedicado a la «sociología de la dominación» desde las estructuras del Estado ${ }^{1}$, el padre del modelo burocrático continental, Max Weber, ya señalaba la importancia capital que dentro de las estructuras administrativas funcionariales tenía la definición de una función directiva altamente profesionalizada y designada al margen de la política y del parlamentarismo.

Desde la teoría moderna de la organización pública y la ciencia de la Administración, existe un consenso bastante asentado que propugna que en las organizaciones públicas el liderazgo institucional reclama necesariamente la interacción entre los directivos "políticos», con legitimidad democrática, y los directivos profesionales de extracción meritocrática, aunque la elaboración de un modelo de dirección política y profesional equilibrado sigue siendo en gran medida una cuestión pendiente para el legislador y un reto de futuro 2; que ya Alejandro Nieto calificó como «una de las grandes cuestiones dilemáticas» sobre la que cualquier reforma administrativa debería pronunciarse en primer término ${ }^{3}$, en línea con lo que la mejor doctrina administrativista ya venía reclamando desde la culminación de las grandes reformas administrativas del tardofranquismo ${ }^{4}$.

Asimismo, es un lugar común afirmar que existe un altamente desarrollado y profesionalizado modo de liderazgo organizativo en el mundo de la empresa que no se corresponde con el de la Administración. Los más recientes análisis subrayan el distanciamiento entre ambos mundos desde la perspectiva de la alta dirección de las organizaciones complejas ${ }^{5}$.

En este contexto, resulta innegable que la relación existente entre los diferentes tipos de liderazgo institucional y los resultados obtenidos en la consecución de sus objetivos por parte de una determinada organización pública constituye una relación de causa-efecto y una de las claves de bóveda de la definición de un modelo institucional eficiente, que evalúe sus políticas y que rinda cuentas. Por ello, la recurrente cuestión de la definición de un modelo estable de directivo público profesional vuelve a ocupar la atención del legislador en cualquier proyecto de reforma o desarrollo del modelo organizativo o del empleo público, acrecentada ahora por el proceso de transformación digital ${ }^{6}$ y por la pandemia sanitaria del COVID-19, que ha desnudado las carencias del sector público haciendo más oportuna que nunca una nueva reflexión sobre cómo afrontar la incertidumbre y el riesgo desde la gestión pública.

1 Economía y Sociedad, trad. de la edición alemana de 1922, vol. II, Fondo de Cultura Económica, Méjico, 1944, Capítulo IX.

2 Basta consultar las obras de referencia en la materia que lo subrayan como un consabido déficit de nuestro modelo legal, cuyas claves esbozamos en este epígrafe. Así, entre otros muchos, pueden destacarse la obra de MAESO SECO, L. F., EI personal directivo público en España: su régimen jurídico antes y después del EBEP, Madrid, La Ley, 2011; y, entre las más recientes, las de RAMIÓ MATAS, C., La Administración pública del futuro (Horizonte 2050): instituciones, política, mercado y sociedad de la innovación, Tecnos, Madrid, 2017; y JIMÉNEZ ASENSIO, R., "La dirección pública profesional: perspectiva comparada y diagnóstico de la situación en España" en la obra colectiva (dirigida por él mismo junto a VILLORIA, M. y PALOMAR OLMEDA), La dirección pública profesional en España, Marcial Pons, 2009, pág. 15 y ss.

3 “Un primer paso para la reforma de la Administración española”, en La reforma del Estado y de la Administración española (dir. por BAENA DEL ALCÁZAR, M.), INAP, 2013, Madrid, pág. 163.

4 Desde que GARCÍA-TREVIJANO FOS, en su Tratado de Derecho Administrativo, volumen I (1970), tratase la cuestión de forma pionera, con un nivel de exhaustividad y profundidad extraño en la manualística clásica.

5 NUÑEZ MARTÍN, A., El nuevo directivo público: claves de liderazgo para la gestión pública, EUNSA, Navarra, 2012; ALBAREDA, A. y LOSADA, C., El empleo público en España: desafíos para un estado democrático más eficaz, Instituto de Estudios Económicos, Madrid, 2017; LAPUENTE, V., y DALHSTROM, C., Organizando el Leviatan: por qué el equilibrio entre políticos y burócratas mejora los Gobiernos, Universidad de Deusto, 2018.

6 RAMIÓ MATAS, C., "El Estado en el año 2050: entre la decadencia y el esplendor", Revista del CLAD Reforma y Democracia, núm. 66, 2016, pág. 5 y ss; y, de mismo autor, "Inteligencia artificial, robótica y modelos de Administración pública", Revista del CLAD Reforma y Democracia, núm. 72, 2018, pág. 5 y ss. Es interesante, en este sentido, consultar las referencias a esta cuestión que se contienen en la llamada Estrategia Española en Inteligencia Artificial, presentada por el Ministerio de Economía del Gobierno de España en diciembre de 2020, así como en el Plan Español de Recuperación, Transformación y Resiliencia (España puede) aprobado en octubre de 2020 como propuesta para la ejecución de los Fondos europeos Next Generation UE. 
A nivel estatal, deben tenerse en cuenta diversos textos legales que aportan la regulación esencial sobre esta cuestión.

En primer lugar, la derogada la Ley 6/1997, de 14 de abril, de Organización y Funcionamiento de la Administración General del Estado (LOFAGE), que establecía un modelo directivo a mitad de camino entre lo politizado y lo funcionarial basado en la distinción entre órganos superiores y directivos, exigiendo que los segundos fuesen desempeñados, en todo caso, por funcionarios de carrera; mientras que los primeros (Ministros y Secretarios de Estado) tenían un claro cariz político ${ }^{7}$. El modelo de la LOFAGE fue reproducido, con algunas variables reseñables, por los artículos 57 a 68 de la Ley 40/2015, de 1 de octubre, de Régimen Jurídico del Sector Público (LRJSP) ${ }^{8}$, que, con carácter general, atribuye a los órganos superiores la principal función de establecer los planes de actuación de la organización situada bajo su responsabilidad y a los órganos directivos su desarrollo y ejecución (art. 55.9)9.

Es de consignar que la LRJSP derogó la Ley 28/2006, de 18 de julio, de Agencias estatales para la mejora de los servicios públicos, que introdujo un régimen para el personal directivo de las Agencias que implantaba la posibilidad de selección por órganos especializados en los que residía la facultad de proponer de manera motivada a tres candidatos, al tiempo que hacía posibles los contratos de alta dirección. Se trataba de una fórmula que pretendía garantizar la transparencia y objetividad en los procesos de nombramiento, que debían efectuarse atendiendo a los criterios de competencia profesional y experiencia entre titulados superiores, preferentemente -pero no exclusivamente- funcionarios, y mediante un procedimiento que garantizase el mérito, la capacidad y la publicidad.

En segundo lugar, el Estatuto Básico del Empleado Público de 2007 (EBEP) y el posterior texto refundido aprobado por el Real Decreto Legislativo 5/2015, de 30 de octubre (TREBEP) que reproduce las previsiones del artículo 13 del EBEP, de carácter básico, para el llamado «personal directivo profesional», con la siguiente fórmula tan abierta como poco detallada:

«El Gobierno y los órganos de gobierno de las comunidades autónomas podrán establecer, en desarrollo de este Estatuto, el régimen jurídico específico del personal directivo así como los criterios para determinar su condición, de acuerdo, entre otros, con los siguientes principios:

1. Es personal directivo el que desarrolla funciones directivas profesionales en las Administraciones Públicas, definidas como tales en las normas específicas de cada Administración.

2. Su designación atenderá a principios de mérito y capacidad y a criterios de idoneidad, y se llevará a cabo mediante procedimientos que garanticen la publicidad y concurrencia.

3. El personal directivo estará sujeto a evaluación con arreglo a los criterios de eficacia y eficiencia, responsabilidad por su gestión y control de resultados en relación con los objetivos que les hayan sido fijados.

4. La determinación de las condiciones de empleo del personal directivo no tendrá la consideración de materia objeto de negociación colectiva a los efectos de esta ley. Cuando el personal directivo reúna la condición de personal laboral estará sometido a la relación laboral de carácter especial de alta dirección».

La introducción en el EBEP de esta figura del personal directivo se consideró por la doctrina una inequívoca oportunidad para la modernización de la función directiva, en el entendido que la regulación de la figura pretende sujetar la gestión profesional a criterios de eficacia y eficiencia, responsabilidad y control de resulta-

7 La LOFAGE asentó la distinción, largamente acogida por la legislación autonómica posterior, entre órganos superiores y directivos de los Ministerios; siendo los primeros los Ministros y Secretarios de Estado, y llegando los segundos hasta el nivel de Subdirección general (comprendiendo, por tanto, a los Subsecretarios y Secretarios Generales -en caso de existir-, Secretarios Generales Técnicos, Directores Generales y Subdirectores). Asimismo, la LOFAGE exigía a los órganos directivos, la condición legal de «funcionarios de carrera del Estado, de las Comunidades Autónomas o de las Entidades locales, a los que se exija para su ingreso el título de Doctor, Licenciado, Ingeniero, Arquitecto o equivalente» (o del subgrupo A1 al que se refiere el art. 76 del TREBEP, como dice hoy la LRJSP). Esta segunda regla no ha tenido, en cambio, tanto predicamento en la legislación autonómica como la primera, lo que hace a las Comunidades Autónomas más proclives a un mayor nivel de politización de la función directiva.

8 Además de reproducir la distinción entre órganos superiores (políticos) y órganos directivos, extiende esta categorización al ámbito de la Administración periférica y en el exterior; mientras que en el caso de los organismos públicos, serán sus Estatutos los que establezcan sus órganos directivos.

9 Al tiempo de escribirse estas líneas, en diciembre de 2020, se está tramitando en el Parlamento la Ley de Presupuestos para 2021, que pretende recuperar la regulación de las Agencias estatales, sin que en el proyecto que hemos manejado se recupere esta figura directiva. 
dos en función de los objetivos ${ }^{10}$. Sin embargo, más de una década después de su regulación en el EBEP, la figura sigue sin contar, al menos en el ámbito de la Administración General del Estado, con el desarrollo normativo que requiere para hacerla operativa como modelo de selección y designación de directivos públicos.

En otro orden, la introducción de la llamada carrera horizontal en el EBEP (art. 17) tampoco ha supuesto el modelo de promoción basado en habilidades directivas ${ }^{11}$.

En tercer y último lugar, también ha de tenerse en cuenta la Ley $3 / 2015$, de 30 de marzo, reguladora del ejercicio del alto cargo de la Administración General del Estado; condición que la LRJSP atribuye a los titulares de los órganos superiores, con la excepción de los Subdirectores generales y asimilados (art. 55.6) ${ }^{12}$.

Como es fácilmente comprobable, al menos en la legislación estatal, la figura del directivo público no pretende superar la idea del funcionario público, sino solaparse con ella para perfilar una categoría distinta orientada al ejercicio de las funciones específicamente directivas.

Dentro del esquema resultante, se presume que la designación de los titulares de los órganos directivos (siempre que tengan la condición funcionarial legalmente exigible en el Estado) corresponde a la libre designación del Ministro o, en su caso, del Consejo de Ministros (cuando una Ley así lo prevea), lo que condiciona enormemente el perfil político de sus titulares, pese a la condición funcionarial que los acompaña. Que el nombramiento se proyecte con la exigencia de que deba recaer en funcionario público no le resta un ápice al carácter político de la designación. Por otro lado, el mero hecho de ser funcionario del Grupo A1 o A2 no representa que la persona designada disponga de las competencias mínimas o básicas para ejercer función directiva. La dirección pública superior en España ofrece, por tanto, un modelo altamente politizado, solo parcialmente corregido (en el ámbito del Estado, no así de las Comunidades Autónomas o de las Entidades Locales) con reservas de designación de determinados ámbitos directivos a favor de funcionarios.

Junto a lo anterior, los niveles directivos intermedios (o de segundo nivel) en las Administraciones Públicas españolas se cubren también, en su mayor parte, por procedimientos de provisión de libre designación entre funcionarios públicos, aunque en algunos casos puntuales esa provisión se hace por concurso específico (por ejemplo, en la Administración vasca o en la andaluza para las Jefaturas de Servicio). Es un sistema de dirección pública intermedia marcado por los altos márgenes de discrecionalidad de la autoridad que tiene la competencia de los nombramientos y ceses. Y no puede hablarse en puridad de una función directiva profesional allí donde no hay procesos competitivos abiertos, o se prevé el libre cese de las personas designadas, aunque estas hayan alcanzado esos niveles directivos tras procesos competitivos formales y aparentemente objetivos.

En todo caso, profesionalizar para dotar de una estabilidad sujeta a criterios de mérito y capacidad determinados puestos clave de la organización de las Administraciones Públicas, sobre todo en un modelo administrativo como el nuestro sumamente dependiente del sector público, que penetra con una capilaridad enorme en el tejido socio-económico y productivo de nuestro país, pasa por profesionalizar la dirección pública. Y -a nuestro juicio- ello no debe implicar funcionarizar, o al menos no debe limitar a esta condición el requisito de entrada en la función directiva profesional. Pues, como gráficamente ha dicho Jiménez Asensio, "se puede ser un excelente funcionario público y, a su vez, un pésimo directivo» ${ }^{13}$.

Como veremos seguidamente, las experiencias de éxito apuntan, antes bien, a los modelos abiertos de selección objetiva a partir de la demostración de una formación específica y de aptitudes directivas que per-

10 Léase, en este sentido, el pionero trabajo del tristemente extrañado BERMEJO VERA, "El personal directivo, ¿nueva tipología de funcionario público?" en AA.VV, El estatuto básico del empleado público y su desarrollo legislativo, Universidad de Zaragoza, 2007, pág. 195 y ss; así como el trabajo de PALOMAR OLMEDA, A., "Pautas para el diseño de un estatuto de directivo público para las administraciones convencionales", Revista Vasca de Administración Pública, núm. 72, 2005, pág. 195 y ss.

11 En relación con la carrera horizontal y la evolución del desempeño a efectos de su aplicación, véase PADILLA RUIZ, P., La evaluación del desempeño en un contexto de mejora de la gestión del empleo público, 2018, tesis doctoral de libre consulta en http:// hdl.handle.net/10578/20351.

12 Desde la perspectiva que interesa a este trabajo, basta con mencionar que esta Ley, en la línea seguida por muchas de sus homónimas autonómicas, establece definitivamente que el nivel de alto cargo llega hasta el de Director General incluido, y que regula los requisitos de idoneidad para el nombramiento de todos ellos, siquiera sea con carácter genérico (estableciendo en sus arts. 2 y 3 unos principios generales que rigen su selección y conducen el ejercicio de la condición de alto cargo). La Ley intenta precisar qué se entiende por idoneidad, al exigir la concurrencia de tres características: honorabilidad, debida formación y experiencia en la materia. Añade, por lo que a la formación y a la experiencia se refiere, que éstas se valorarán teniendo en cuenta los «conocimientos académicos adquiridos», sin que se exija titulación universitaria, y la «naturaleza, complejidad y nivel de responsabilidad de los puestos desempeñados, que guarden relación con el contenido y funciones del puesto para el que se le nombra».

13 Op. cit. supra, pág. 43. Idea previamente desarrollada, por el mismo autor, en su trabajo "Los directivos públicos en la reforma del empleo público: especial consideración del personal directivo local" en El estatuto básico del empleado público y su incidencia en el ámbito local (coord. por PALOMAR OLMEDA, A.) 2007, pág. 165 y ss. 
miten que el talento entre y salga de manera natural de la Administración sin precondicionar las competencias del directivo público profesional a la necesaria condición de funcionario público, pero sin que tampoco sea tal condición un obstáculo para ello.

\section{AVANCES DEL LEGISLADOR AUTONÓMICO A PARTIR DE LAS PREVISIONES BÁSICAS DEL EBEP Y ALGUNAS EXPERIENCIAS RELEVANTES DE DERECHO COMPARADO}

Según recientes informes de la ODCE, España es el país de los de mayor tamaño de la Unión Europea que tiene una dirección pública con estándares más bajos de profesionalización y con una mayor presencia de la politización y de nombramientos discrecionales en tales estructuras, lo que representa un importante déficit estructural del modelo de gobierno abierto ${ }^{14}$

La falta de desarrollo del artículo 13 del TREBEP, unida a la desestructurada legislación estatal a la que nos hemos referido, que condiciona, de un lado, el acceso a la titularidad de órganos directivos a la condición funcionarial y, de otro, establece un sistema sumamente discrecional en la selección y cese de tales puestos, ha animado a algunas Comunidades Autónomas, en el marco de sus competencias de autoorganización y de desarrollo del régimen jurídico básico de sus empleados públicos a ensayar fórmulas más o menos imaginativas e innovadoras de implantación dela figura del directivo público profesional.

Por orden cronológico destaca, en primer lugar, la pionera Ley 3/2007, de 27 de marzo, de la Función Pública de la Comunidad Autónoma de las Illes Balears, que desarrolló la categoría del «directivo público» pocos días antes de la aprobación del EBEP, pero a la luz del art. 13 del mismo, abriendo la posibilidad a que personal no empleado público pudiese desempeñar funciones directivas. A tal efecto, la Ley establece la posibilidad de configurar la naturaleza directiva de determinados puestos en las correspondientes Relaciones de Puestos de Trabajo (estableciendo dicha condición, en todo caso, para los puestos de nivel 30 y los que impliquen jefatura de departamento o de servicio cuando tienen dependencia directa del órgano superior o directivo al cual están adscritos), que atribuirían a los mismos funciones de dirección, programación, coordinación, impulso y evaluación de la actuación administrativa o técnica, en los distintos ámbitos de la Administración. Según el art. 35 de la Ley balear, los puestos de trabajo de naturaleza directiva requieren para su ocupación el diploma de personal directivo expedido por la Escuela Balear de Administración Pública u otro homologado por ésta, estando sujetos quienes obtengan dicho diploma a los sistemas de evaluación del cumplimiento regulados en la propia Ley.

Posteriormente, la Ley $1 / 2014$, de 18 de febrero, de regulación del estatuto de los cargos públicos del Gobierno y la Administración de la Comunidad Autónoma de Extremadura definió la figura del personal directivo que dichos puestos pudieran ser desempeñados en virtud de contratos sometidos a la relación laboral de alta dirección, para aquellos casos en los que las normas generales de función pública de Extremadura así lo prevean para los funcionarios, docente o personal laboral. Posteriormente, la Ley 13/2015, de 8 de abril, de Función Pública de Extremadura incluyó la rendición de cuentas como elemento íntimamente ligado a la carrera horizontal y al grado de desempeño del personal directivo. Asimismo, la legislación extremeña establece la disposición de objetivos y el resultado de la evaluación del desempeño como elementos relacionados con la remuneración de directivos, al tiempo que reconoce la situación de servicios especiales al personal sometido a la relación laboral de alta dirección.

14 Si utilizamos como referencia el porcentaje de ingresos o gasto público respecto al PIB y el porcentaje que representa el empleo público respecto del total, España está en la media de países desarrollados. Según la OCDE también se han cumplido en nuestro país los compromisos de la Alianza Internacional por el Gobierno Abierto (Open Government Partnership), a la que España se sumó en 2011. Fruto de estos compromisos, España ha culminado ya cuatro planes estratégicos de gobierno abierto, habiendo aprobado el último en 2020 para el periodo 2020-2024. Sin embargo, nuestro país está a la cola en la profesionalización de la función directiva, que es señalada por la OCDE como una de las claves para avanzar en el fortalecimiento institucional. Tal deficiencia ya se hizo presente en el Informe OCDE Survey on Strategic Human Resources Management in Government de 2006, del que puede consultarse una versión actualizada de 2016 en http:// www.oecd.org/gov/survey-on-strategic-human-resources-management-2016.pdf, y ha vuelto a relucir en la base de datos elaborada por la unidad especializada de la OCDE sobre Public Employment and Management working party (PEM), de libre acceso en http://www.oecd. org/gov/government-at-a-glance-2017-database.htm. Asimismo es de interés el documento Engaging public employees for a high performing civil service, Paris, OCDE Publishing, 2016 (https://www.oecd.org/gov/engaging-public-employees-for-a-high-performing-civil-service9789264267190-en.htm). Si acudimos a otros marcos internacionales de contraste, las conclusiones son parecidas. Así, España recibe una baja valoración de la imparcialidad de los funcionarios públicos en el Informe sobre Competitividad Global 2017 elaborado por el Foro Económico Mundial (situándose en el puesto núm. 83 de los 137 países analizados). Este resultado se corrobora en los indicadores de efectividad gubernamental elaborados por el Banco Mundial en 2018, en los que España ocupaba un mediocre puesto número 12 de la Unión Europea. 
Por su parte, la Comunidad de Castilla-La Mancha aprobó mediante Decreto 215/2019, de 30 de julio, del Estatuto de la Dirección Pública Profesional de la Administración de la Junta de Comunidades de Castilla-La Mancha, que desarrolla las previsiones que sobre el personal directivo profesional contenía la Ley 4/2011, de 10 de marzo, del Empleo Público de dicha Comunidad Autónoma. La figura se califica como un elemento decisivo para la modernización administrativa, sometiendo su selección a requisitos y procedimientos específicos, y su gestión a al cumplimiento de objetivos y control de resultados en función de su grado de consecución ${ }^{15}$.

En el ámbito de la Administración de la Comunidad Autónoma de las Islas Canarias, la Resolución de 14 de noviembre de 2019 dispone la publicación del Acuerdo del Consejo de Gobierno canario que dicta Instrucciones a los representantes del Gobierno en las Juntas Generales y Consejos de Administración de las sociedades mercantiles públicas relativas al personal directivo de dichas sociedades. Esta disposición, de ínfimo rango, se ampara en la legislación canaria de Transparencia y Acceso a la información pública, en la legislación autonómica sobre sociedades mercantiles dependientes o vinculadas a la Administración insular y en el Decreto 68/2015, de 30 de abril, por el que se establece el marco general para la innovación y mejora de los servicios públicos de la Administración Pública de la Comunidad Autónoma de Canarias, para establecer un modelo de selección del personal directivo de las sociedades mercantiles del sector público canario basado en la acreditación de capacidades y experiencia previa en la gestión y en la evaluación periódica de resultados a partir de un programa de gestión que tendrá su origen en el plan organizativo y de funcionamiento que los candidatos seleccionados hayan presentado y defendido en las pruebas de selección.

Junto a estas medidas, en el momento de redactarse estas líneas existen otras iniciativas autonómicas en marcha. Así, a principio del 2019 el Gobierno Vasco presentó un proyecto de Ley de Empleo Público que define la figura del Alto Cargo y Directivo Público Profesional y determina las funciones directivas. El sistema de selección se fundamenta en la valoración y acreditación de competencias. Más recientemente, la Comunidad andaluza ha avanzado su intención de regular la figura del directivo público profesional en su anunciada reforma de la Ley 6/1985, de 28 de noviembre, de Ordenación de la Función Pública de la Junta de Andalucía.

Muchas de estas regulaciones e iniciativas autonómicas han partido del análisis comparado de algunos modelos contrastados en nuestro entorno más próximo que han avanzado en las últimas décadas reformas institucionales de profesionalización de la dirección pública.

De los distintos modelos comparados actuales, se podrían destacar, por su proximidad al modelo español o por su reconocimiento a nivel internacional, los siguientes:

\section{a) El «senior civil service» británico}

Tras la aprobación del Civil Service Management Code de 1 de abril de 1996, la figura de Senior Civil Service se configura como una categoría singular del directivo público de la Administración británica que cuenta con un estatuto diferenciado del resto de empleados públicos en cuanto a selección, estructura retributiva e incentivos al rendimiento y objetivo de evaluación y cumplimiento ${ }^{16}$.

Para los puestos de mayor relevancia, que se corresponden con determinadas «bandas» salariales, la selección se realiza directamente mediante la Civil Service Commission, con arreglo a un protocolo específi-

15 La Ley 4/2011, de 10 de marzo, no identificó directamente ningún puesto de carácter directivo, pero facultó al Gobierno autonómico para que, a través de la correspondiente relación de puestos de trabajo, determinase qué puestos tienen ese carácter, limitándose a señalar que los puestos directivos debían ser desempeñados por personal funcionario de los subgrupos A1 o A2 de cualquier Administración pública o, excepcionalmente, por personas que no provengan de la función pública. Junto a ello, la Ley 4/2011 exigió acreditar competencias directivas, habilitando al desarrollo reglamentario para determinar cuándo aquéllas deben entenderse acreditadas. De acuerdo con ello, el citado Decreto 215/2019 establece los requisitos que deben cumplirse para que un puesto de trabajo pueda ser calificado como personal directivo en las RPT, regulando a su vez las formas en que se han de acreditar las competencias directivas, previéndose básicamente dos: a través de la formación específica sobre dirección pública -ya sean cursos de formación organizados por Administraciones públicas o títulos oficiales de Máster o postgrado- y a través de la experiencia profesional por el desempeño de puestos directivos o asimilados. Por otro lado, se establecen las normas para la provisión de dichos puestos mediante procedimientos que garanticen la publicidad y la concurrencia. Respecto del Estatuto del personal directivo, se prevé el régimen de responsabilidad del cumplimiento de los objetivos asignados; la forma en que se determinan esos objetivos, contemplándose la figura de un programa de gestión anual; así como los indicadores que permiten evaluar su cumplimiento con carácter anual y las consecuencias de esa evaluación, incluyendo las retributivas en función del grado de cumplimiento de los objetivos señalados.

16 FOX, B., "Creating the senior civil service", Rivista trimestrale di diritto pubblico, núm. 3, 1999, pág. 819 y ss. 
co y con el apoyo en una Comisión designada ad hoc ${ }^{17}$, mientras que en el resto de los puestos la selección es responsabilidad del Departamento o Agencia convocante ${ }^{18}$. Pero en ambos casos los procesos selectivos se desarrollan conforme a similares criterios de publicidad, concurrencia y evaluación del mérito que están plasmados en la Constitutional Reform and Governance Act de 2010.

La Comisión tiene un programa de supervisión de la capacidad y el cumplimiento para garantizar que la selección para el nombramiento en la función pública en otros niveles cumpla con los requisitos legales, que se basa en un contrato-programa y la evaluación periódica del desempeño cada dos años ${ }^{19}$.

\section{b) El sistema francés de los «emplois de direction»}

El Estatuto de la función pública en la Administración francesa está unificado para las distintas Administraciones territoriales desde la Ley de 13 de julio de 1983. En Francia existe un sistema de provisión de los puestos de carácter directivo, denominados «emplois de direction», a nivel de subdirector general y jefaturas de servicio, que rige para la Administración central, institucional, Autoridades independientes y órganos de relevancia constitucional, que se clasifican en dos grupos en atención a la importancia de las responsabilidades asignadas. El Decreto n. ${ }^{\circ}$ 2012-32 de 9 de enero de 2012 regula las condiciones para su designación, sujetando dichos nombramientos a una reserva general de provisión por cuerpos de funcionarios específicos que estén en posesión de un determinado grado de antigüedad, por lo que se trata de un sistema cerrado o funcionarizado de acceso a la función directiva.

El procedimiento de selección parte de la publicación de las vacantes en los Diarios correspondientes y en la página web de función pública ${ }^{20}$. El anuncio debe describir pormenorizadamente las funciones, las competencias requeridas y el grupo de clasificación de los empleos vacantes. Una vez examinadas las solicitudes recibidas en el plazo de 30 días desde la publicación del anuncio, las autoridades competentes (los Ministrerios de adscripción del puesto, los directores de los organismos públicos o de las autoridades independientes, o los vicepresidentes del Consejo de Estado y del Tribunal de Cuentas) han de elevar una propuesta de designación motivada para su aprobación por decreto adoptado en Consejo de Ministros (artículo 25 del Estatuto General).

\section{c) El exitoso modelo de la CReSAP portuguesa}

Una de las consecuencias de las reformas impuestas por el Memorándum de Entendimiento que motivó la intervención de la República portuguesa por el Eurogrupo y el Ecofin en el contexto de la crisis financiera de la pasada década, fue la regulación de un modelo profesionalizado de selección de los directivos públicos, dadas las deficiencias y el clientelismo que se le achacaba a la Administración portuguesa. Los objetivos que se marcaron para la reforma del modelo fueron: aproximar el modelo público al régimen laboral común, respetando las especificidades de la Administración; establecer un modelo de gestión por objetivos de servicio, con mantenimiento de la perspectiva de carrera para los directivos; hacer prevalecer la evaluación de méritos en el desarrollo profesional; fortalecer los poderes de gestión de los administradores y los mecanismos de rendición de cuentas.

17 Para la banda de pago 2 (directores), banda 3 (director general) y secretario permanente del servicio civil superior. La Comisión también presiden los concursos internos en la banda de pago 3 de senior civil service y el nivel de Secretario Permanente bajo los términos del Protocolo de Nombramientos de Alto Nivel, acordado con el Jefe del Servicio Civil.

18 https://civilservicecommission.independent.gov.uk/.

19 Los directivos designados han de suscribir un contrato de duración indefinida con el departamento correspondiente, que dispone autónomamente el grado del puesto y la escala salarial aplicable, así como el sistema de incentivos al rendimiento. En el contrato han de especificarse los objetivos anuales y el sistema de evaluación, que ha de analizar los resultados efectivamente alcanzados, la eficiencia en el manejo de los recursos, el desarrollo de las capacidades del equipo y la contribución a la misión u objetivos generales de la organización. El procedimiento de evaluación responde al modelo de 360 grados, en el que participa el personal del servicio, otros directivos públicos, así como los ciudadanos o asociaciones representativas del área de actividad del puesto. En función del resultado de la evaluación, los directivos son clasificados en tres niveles de rendimiento: el $25 \%$, en el de máximo rendimiento; el $65 \%$, en el de rendimiento intermedio; y el $10 \%$ restante, en el de menor rendimiento. Para quienes estén en este último caso se proponen programas de formación directiva individualizados para tratar de atajar las deficiencias des desempeño detectadas en la evalución. En los supuestos en que persista un bajo rendimiento, se aplica un procedimiento específico que comprende un primer aviso por escrito seguido de un período de evaluación de doce meses. Si a lo largo de este período la situación no mejora, se dicta una segunda resolución. El directivo dispone de un plazo para recurrir ante un responsable de recursos humanos, quien le notificará la decisión definitiva, que puede incluir una pérdida del grado o bien el despido.

20 https://www.fonction-publique.gouv.fr/fonction-publique-france. 
Con esta finalidad la Ley n. ${ }^{\circ} 64 / 2011$, de 22 de diciembre, creó la Comissão de Recrutamento e Selecção para a Administração Pública (CReSAP), como autoridad independiente cuya misión es la de reclutar y seleccionar los candidatos de la dirección superior de la Administración estatal portuguesa y de los puestos directivos de las empresas públicas con arreglo a criterios de mérito, equidad y transparencia. La CReSAP se ha convertido en una institución con reconocimiento internacional y un ejemplo de buenas prácticas en relación con la selección de los directivos públicos ${ }^{21}$.

A diferencia de otros modelos, y en ello radica probablemente su éxito, es que la CReSAP no tiene competencias de selección, sino que -más modestamente- se limita a funciones de propuesta a partir de parámetros técnicos y objetivos ${ }^{22}$. Conforme a la Ley n. ${ }^{0}$ 128/2015, de 3 de septiembre, que aprobó sus Estatutos, y al Decreto n. ${ }^{\circ} 14678 / 2015$, de 11 de diciembre que estableció su Reglamento interno, la intervención de la CReSAP se activa a instancias del órgano que haya de designar al candidato. La CReSAP desarrolla todo el proceso de selección y formula una propuesta con tres candidatos al órgano de designación. Tras el desarrollo del proceso emite una opinión basada en una evaluación de competencias, pero su opinión no es vinculante para la autoridad de designación, que puede apartarse de la propuesta o incluso rechazarla. Si uno de los candidatos propuestos por la CReSAP es finalmente nombrado dispone de un período de desempeño de 5 años. A la designación se acompaña la carta de missao, que constituye un compromiso de gestión en la que se definen los objetivos, debidamente cuantificados y calendarizados, que el candidato designado debe aceptar, lo que supone su sujeción a un sistema específico de evaluación del desempeño.

\section{d) Las experiencias de Argentina, Chile y Perú}

Algunos países latinoamericanos de la cuenca sur han adoptado en los últimos años fórmulas inspiradas en alguno de los precedentes comparados que acaban de apuntarse.

Así, en Argentina, en desarrollo de la Ley núm. 24.185 y tras la fusión en el año 2015 del Instituto Nacional de Administración Pública (INAP) con la Escuela Superior de Gobierno, el Decreto N. ${ }^{\circ}$ 254/2015 propició la revisión de los procesos concursales y de selección de personal al servicio de la Administración argentina. En desarrollo de sus previsiones, el Decreto N. ${ }^{\circ}$ 788/2019 establece un nuevo régimen de Alta Dirección Pública (aún no implementado) que establece un régimen singular de relación de empleo para la Alta Dirección Pública basado en mecanismo de selección objetivos y transparentes que pretenden garantizar la selección de este personal en régimen de igualdad de oportunidades y de méritos objetivos para determinar su idoneidad para el ejercicio de los puestos directivos. La selección se base en un régimen de convocatoria pública «abierto», que resuelve un Comité de Selección ad hoc que actúa bajo las pautas de una «Coordinación Concursal». La posición del personal de Alta Dirección Pública tiene una duración de cinco años contados a partir de la toma de posesión, y requiere para su adquisición: a) la prestación efectiva de servicios por un plazo no inferior al requerido para cumplimentar la primera evaluación de desempeño; b) la aprobación de la primera evaluación de desempeño con una calificación no inferior a «bueno», efectuada de conformidad con los parámetros de evaluación establecidos en el citado Decreto 788/2019; y c) la aprobación del Curso de Inducción impartido por el INEA argentino. La designación se somete a un sistema periódico de evaluación del desempeño de carácter anual, instrumentado a partir de la actividad de «evaluadores externos» ${ }^{23}$.

Por su parte, el Sistema de Alta Dirección Pública chileno ha recibido su actual conformación tras las propuestas del Consejo de Alta Dirección Pública y las recomendaciones de la Agenda de Probidad y Transparencia de mayo adoptada por el Senado de la República el 9 de agosto del año 2016, promulgada el 3 de octubre bajo la veste de programa de regeneración y modernización del Estado chileno. El sistema, al que había dado carta de naturaleza la anterior Ley 20.955 perfeccionamiento de las Administraciones Públicas, tiene como objetivo dotar a las Administraciones e instituciones de Gobierno, a través de concursos públicos y transparentes desarrollados por el Consejo de Alta Dirección Pública ${ }^{24}$, con el fin de seleccionar directivos

21 https://www.cresap.pt/.

22 El CReSAP está integrado por un presidente, de tres a cinco miembros permanentes, un miembro no permanente por cada Ministerio y sus respectivos suplentes. En la CReSAP se integra un grupo de expertos, conformado por 20 a 50 miembros designados entre empleados públicos con reconocido mérito profesional, credibilidad e integridad personal que apoyan técnicamente al CReSAP en asuntos específicos y participan en los jurados de concursos de alta gerencia para puestos directivos en la Administración Pública.

23 https://www.argentina.gob.ar/anmat/transparencia/autoridades-personal.

24 Para disminuir el impacto de los cambios de gobierno la nueva normativa elimina la figura de los directivos transitorios y provisionales y los reemplaza por «subrogantes legales» o por «directivos de segundo nivel jerárquico» del mismo servicio elegidos por la 
con probada capacidad de gestión y liderazgo para ejecutar de forma eficaz y eficiente las políticas públicas definidas por las autoridades gubernamentales ${ }^{25}$.

En Perú, la creación de la Autoridad Nacional del Servicio Civil (SERVIR) ${ }^{26}$, en noviembre de 2008, como entidad adscrita a la Presidencia del Consejo de Ministros, con la misión específica de modernizar la función pública peruana, permitió conseguir dos retos principales: la creación de un cuerpo de Gerentes Públicos y la promulgación de una Ley de Servicio Civil (recientemente reformada en 2020) que contempla dentro de la categoría de los empleados de la Administración la figura del directivo público, que define como el servidor civil que desarrolla funciones relativas a la organización, dirección o toma de decisiones de un órgano, unidad orgánica, programa o proyecto especial, cuyo desempeño se sujeta a una evaluación anual por objetivos ${ }^{27}$.

\section{RASGOS DEFINIDORES DEL ESTATUTO DEL DIRECTIVO PÚBLICO A PARTIR DE LAS RECOMENDACIONES DE LA OCDE: CLAVES PARA UNA PROPUESTA}

En 2017, la Organización para la Cooperación y el Desarrollo Económico (OCDE) elaboró un Informe titulado "Liderazgo para un servicio público de alto rendimiento" el que analizaba las capacidades de los empleados públicos de los países más avanzados de la OCDE para afrontar los retos de la globalización y la digitalización de una Administración del siglo XXI. El Informe, que emplea la metodología del análisis de casos, identifica las habilidades necesarias para «gestionar mejores políticas, trabajar de forma eficaz con los ciudadanos y los usuarios de los servicios, gestionar la prestación de servicios eficaces y colaborar con las partes interesadas en entornos en red» y recomienda la implantación de modelos de profesionalización de la gestión directiva pública basados en el reclutamiento por capacidades mesurables de forma objetiva mediante un sistema de acreditación independiente y la evaluación del desempeño ${ }^{28}$. El Informe decanta en buena medida los trabajos previos de la unidad especializada de la OCDE sobre Public Employment and Management (PEM) y concreta las recomendaciones de los Informes periódicos de seguimiento y las encuestas sobre gestión estratégica de recursos humanos en los Gobiernos de los países OCDE ${ }^{29}$.

El citado Informe, y los trabajos anteriores mencionados, dieron lugar a la adopción de una Recomendación del Consejo de la OCDE sobre "Liderazgo y Capacidad en la Función Pública", que constituye el instrumento jurídico más avanzado en la materia ${ }^{30}$. La Recomendación fue formalmente adoptada el 17 de enero de 2019 por el Consejo a propuesta del Comité de Gobernanza Pública. En ella se destaca que una función pública profesional, competente y eficaz es un factor fundamental para fomentar la confianza de los ciudadanos en las instituciones públicas. La Recomendación enuncia 14 principios que tienen por objeto determinar

Alta Dirección Pública. Establece una cuota de hasta 12 cargos de Alta Dirección Pública de primer nivel, correspondientes a jefes de servicio, que el Presidente de la República puede nombrar directamente durante los primeros tres meses de su mandato. Establece la exigencia de contar con acuerdo del Consejo de Alta Dirección Pública para llevar a cabo concursos en los 8 meses finales de un gobierno, y obliga asimismo a efectuar una comunicación fundada previa al Consejo de Alta Dirección Pública para pedir la renuncia de Altos Directivos Públicos de segundo nivel jerárquico, durante los primeros 6 meses desde la toma de posesión de un nuevo Gobierno.

25 https://www.serviciocivil.cl/sistema-de-alta-direccion-publica-2/.

26 https://www.gob.pe/servir.

27 Según los arts. 58 a 64 de la Ley peruana de Servicio Civil, el directivo público tiene funciones de organización, dirección o toma de decisiones sobre los recursos a su cargo, y vela por el logro de los objetivos asignados y supervisa el logro de metas de los servidores civiles bajo su responsabilidad. El ingreso a un puesto directivo público se realiza por concurso público de méritos realizado por cada entidad, cumpliendo con el perfil del puesto respectivo. Los directivos públicos son asignados para desempeñar puestos hasta el tercer nivel orgánico consecutivo de la entidad por un plazo de tres años renovable, siempre que cuenten con evaluaciones positivas de desempeño.

28 El documento es el resultado de un proyecto en el que nueve países solicitaron a la OCDE que desarrollase estudios «de caso» sobre los desafíos específicos de liderazgo que han de ejercer las organizaciones públicas. Los estudios de casos concretos se desarrollaron a través de diferentes métodos, basados en una estrecha interacción con altos funcionarios de los países participantes. Estos nueve estudios de caso también se utilizaron para generar discusión y debate en cuatro talleres a los que asistieron participantes de todos los países OCDE. Algunos de los estudios analizaron capacidades de liderazgo particulares. Por ejemplo, Finlandia pidió a la OCDE identificar desafíos y oportunidades para promover la colaboración entre organizaciones. Los países bajos querían promover a los altos funcionarios como «socios sociales». Canadá quería explorar el liderazgo inclusivo. E Irlanda y Francia propusieron analizar los retos la innovación y liderazgo de la tecnología digital. El Informe se puede consultar en http://www.oecd.org/fr/gov/skills-for-a-highperforming-civil-service-9789264280724-en.htm.

29 Accesibles en http://www.oecd.org/gov/pem/.

30 Existe una versión en castellano en http://www.oecd.org/gov/pem/recomendacion-del-consejo-sobre-liderazgo-y-capacidaden-la-funcon-publica.pdf. 
qué es lo que hace que una función pública sea adecuada, responda a las necesidades actuales y contribuya a garantizar que siga siéndolo en el futuro, y permita al mismo tiempo presentar estrategias para lograr y promover un buen desempeño y un servicio de calidad para los ciudadanos. La Recomendación promueve «una Administración con un alto nivel de profesionalidad que se basa en la objetividad, la imparcialidad y el Estado de Derecho como condiciones fundamentales para garantizar la confianza de los ciudadanos en las instituciones públicas y la gobernanza». A partir de lo anterior, la Recomendación pretende «mejorar las formas de organización y gestión de los servidores públicos para hacer hincapié en la colaboración proactiva y la innovación al servicio de los ciudadanos así como en las actividades económicas que protejan el valor público y el interés común».

Partiendo de dichas recomendaciones y de los Informes y documentos precedentes ${ }^{31}$, es posible desgranar un conjunto de elementos que conforman el modelo OCDE para la definición de las capacidades de los directivos públicos profesionales y el establecimiento de un sistema de selección y desempeño de los mismos que pueden resumirse del siguiente modo ${ }^{32}$ :

- Desde la perspectiva de la planificación y estabilidad del diseño, se recomienda desarrollar de forma permanente y mediante una política específica de Recursos Humanos las capacidades de liderazgo de los servidores públicos de alto nivel actuales y potenciales. Dicha planificación precisa la previa definición de los puestos de carácter directivo en cada organización.

- El Estatuto del personal directivo ha de partir del establecimiento de estándares o indicadores competenciales basados en los méritos y la formación directiva específica, que aseguren la imparcialidad, la integridad y la capacidad de liderazgo de los directivos públicos profesionales. A tal efecto, se recomienda considerar todos los aspectos relevantes de la gestión de personas y garantizar su alineación con los procesos de planificación estratégica del gobierno, incluida la gestión del presupuesto.

- Es preciso establecer un sistema de selección transparente y abierto, en el que se fijen estándares de evaluación del desempeño a partir del cumplimiento de objetivos prefijados para cada puesto mediante la fijación de valores de servicio público que guíen la relación y la toma de decisiones y permitan la rendición de cuentas por el desempeño.

- Los objetivos del mandato deben proporcionar orientaciones de dirección para los directivos profesionales y estar alineados con los objetivos políticos del Gobierno y de las autoridades políticas.

- El cumplimiento de los objetivos del mandato ha de estar emparejado con niveles adecuados de autonomía y responsabilidad para alcanzarlos sin temor a represalias políticas, como resultado de un asesoramiento imparcial basado en el conocimiento experto y la libertad de decir la verdad (speech the truth). Ello pudiera hacer aconsejable incluso -en algunos casos al menos-, establecer un mandato temporal desligado de la esfera política, así como el establecimiento de un sistema de cese por causas objetivas. Se recomienda, asimismo, regular los conflictos de interés.

- Definir y ofrecer condiciones de empleo transparentes (por ejemplo, remuneración, duración de los contratos, seguridad en el empleo, derechos y obligaciones) que se correspondan debidamente con las funciones de cada puesto directivo, teniendo en cuenta los mercados de trabajo externos (del sector privado) e internos.

- Establecer un sistema de supervisión eficaz y mecanismos ágiles y efectivos de presentación y tramitación de las las reclamaciones que puedan formularse. Ello reclama definir la autoridad institucional responsable del sistema de selección en cada Administración pública y dotarla de un estatus de independencia a tal efecto.

31 Además de los trabajos del PEM antes mencionados, la Recomendación sobre Liderazgo y Capacidad en la Función Pública cita como precedentes otras Resoluciones del Consejo de la OCDE: En concreto: la Recomendación del Consejo para mejorar la Calidad de la Regulación Gubernamental [OCDE/LEGAL/0278], la Recomendación del Consejo sobre las Directrices de la OCDE para la Gestión de Conflictos de Intereses en la Función Pública [OCDE/LEGAL/0316], la Recomendación del Consejo sobre Política y Gobernanza Regulatorias [OCDE/LEGAL/0390], la Recomendación del Consejo sobre la Igualdad de Género en la Educación, el Empleo y la Actividad Empresarial [OCDE/LEGAL/0398], la Recomendación del Consejo sobre la Igualdad de Género en la Vida Pública [OECD/ LEGAL/0418] y la Recomendación del Consejo sobre Integridad Pública [OECD/LEGAL/0435].

32 La OCDE utiliza habitualmente los siguientes indicadores para determinar si una Administración dispone de un sistema de dirección pública profesional: $1 .^{\circ}$ Existencia de una carrera separada para los directivos públicos; $2 .^{\circ}$ Promoción de la movilidad de los directivos públicos; $3 .^{\circ}$ Reclutamiento a través de un procedimiento centralizado; $4 .^{\circ}$ Existencia de un periodo de nombramiento de los directivos públicos; $5 .^{\circ}$ Vinculación de la actuación de los directivos públicos al cumplimiento de objetivos; y, $6 .^{\circ}$ Posibilidad de cese de directivos públicos en caso de rendimiento insuficiente. 
Muchas de estas recomendaciones fueron recogidas por la propuesta de Estatuto del personal directivo público presentada por la Asociaciones de Cuerpos Superiores de la Administración Civil del Estado (FEDECA) a finales de 2018 que, hasta el momento, nos parece la propuesta más seria y sopesada para desarrollar este crucial aspecto en el ámbito de la Administración General del Estado (AGE) y sus organismos públicos ${ }^{33}$.

La propuesta sitúa la figura del directivo público profesional en el ámbito que media entre la dirección política y la Administración, asumiendo que su función consistiría en formular las políticas públicas en consonancia con los ejes de la acción de Gobierno, planificar y movilizar los apoyos necesarios, y ejecutar aquellas de forma eficiente y mensurable a partir de los recursos humanos y materiales que estén bajo su responsabilidad.

En este sentido, desde un punto de vista orgánico, la figura del directivo público podría coincidir con la del «órgano directivo» que se recoge en la LRJSP (como propone FEDECA) ${ }^{34}$, si bien es cierto que su implantación en el ámbito autonómico se ha movido en niveles inferiores ${ }^{35}$. En todo caso, parece claro que la figura debería adecuarse en algún nivel de "órgano directivo», dentro de la vigente distinción entre órganos superiores y directivos ${ }^{36}$, en el entendido de que los órganos superiores, de clara confianza política del Gobierno, quedarían fuera del ámbito de un Estatuto del directivo público profesional.

Desde un punto de vista funcional, se debería considerar personal directivo solo a aquellos cargos que desarrollan funciones de especial relevancia para la organización, incluyendo el establecimiento y evaluación de objetivos; el diseño, planificación y gestión de proyectos; la dirección de personas y gestión de recursos presupuestarios; así como la participación en la formulación de políticas públicas con algún margen de autonomía y responsabilidad reconocible de acuerdo con parámetros objetivos previamente definidos.

En todo caso, sería precisa la elaboración de un catálogo de puestos directivos que clarifique las funciones profesionales de este tipo de empleo público, lo que no puede hacerse sino mediante las oportunas referencias en las RPT correspondientes.

Tras la definición de estos puestos en la esfera de mando intermedia que estamos considerando, sería necesaria la regulación de aquellos aspectos previos que acrediten, de forma genérica y previa, y sin perjuicio de las pruebas específicas que para el desarrollo de cada puesto concreto se requieran, a quienes pueden desempeñar puestos directivos.

Es una cuestión debatible si dichos nombramientos deben realizarse entre funcionarios públicos (como sostiene la propuesta de FEDECA) o cabe la designación de personal no funcionario que acredite las oportunas competencias, como alguna legislación autonómica ha reconocido expresamente -siquiera sea con carácter excepcional- y es habitual en los modelos comparados (con la excepción del francés), lo que nos parece plausible.

El procedimiento de selección debe ser público, transparente y competitivo, previa identificación del puesto (y perfil) que se pretende cubrir mediante convocatoria pública.

La formación específica y la acreditación de competencias directivas debería ser un requisito para poder concursar a un puesto de esa naturaleza. Asimismo, hemos visto que una de las claves del éxito en la selección de los directivos públicos en el Derecho comparado consiste en residenciar la competencia para acreditar el mérito y capacidad de los candidatos y seleccionar a los más idóneos en una autoridad especializada en este cometido, siquiera sea a nivel de propuesta (como la terna que eleva la CReSAP portuguesa) al órgano superior competente para la designación.

33 Propuesta que puede consultarse en https://fedeca.es/prensa/presentaci\%C3\%B3n-de-fedeca-de-su-propuesta-de-estatutodel-directivo-p\%C3\%BAblico.

34 En concreto, la LRJSP señala como órganos directivos a los Subsecretarios y Secretarios generales, los Secretarios generales técnicos y Directores generales y a los Subdirectores generales. En la organización territorial de la AGE son órganos directivos tanto los Delegados del Gobierno en las Comunidades Autónomas, con rango de Subsecretario, como los Subdelegados del Gobierno en las provincias, con nivel de Subdirector general. En la Administración exterior del Estado, son órganos directivos los embajadores y representantes permanentes ante Organizaciones internacionales. Asimismo, la LRJSP prevé que los estatutos de los Organismos públicos determinen sus respectivos órganos directivos.

35 A grandes rasgos, y con carácter general, la franja en la que ubican la figura las Comunidades Autónomas que la han implantado son los puestos de nivel 28 a 30 que median entre una Subdirección y una jefatura de servicio, incluyendo los puestos de coordinación, conservando la designación «política» del nivel de Director General.

36 La LRJSP cita como órganos superiores a los Ministros y Secretarios de Estado y como directivos al resto de órganos antes citados. Distingue entre ambos al decir que corresponde a los órganos superiores establecer los planes de actuación de la organización situada bajo su responsabilidad y a los órganos directivos su desarrollo y ejecución. 
Es un denominador común en los modelos que hemos analizados que, con independencia de la duración del mandato (punto en el que los modelos difieren enormemente ${ }^{37}$ ) la ejecutoria del directivo público esté sujeta a la consecución de una serie de objetivos preconfigurados desde el nombramiento (carta-mandato, contrato programa, etc.), que estén en consonancia con el detalle de los planes y programas anuales y plurianuales que afecten su actividad. Consecuentemente con ello, es habitual sujetar a evaluación continua (anual o/y plurianual) el cumplimiento de dichos objetivos de acuerdo a un modelo de evaluación del desempeño y de rendición de cuentas articulado a partir del grado de cumplimiento del contrato programa, cohonestando los resultados con el reconocimiento de incentivos por productividad o las remuneraciones anuales del puesto, así como ligar el carácter renovable del nombramiento al resultado de la evaluación final del desempeño.

En otro orden, el régimen de cese, que debe ser reconducido a tipos tasados previos que eviten la discrecionalidad política, y el régimen de incompatibilidades debería ser también específico, si bien deberían modularse las rigideces del régimen ordinario de incompatibilidades de los altos cargos (al que alguna legislación autonómica se remite in totum y acríticamente).

Un último aspecto relevante del Estatuto del directivo público profesional debería ser la configuración de un código deontológico específico. Como sugiere la propuesta de FEDECA, «la actuación de los directivos públicos proyecta la imagen de la institución ante la sociedad. Para que esta imagen permita fortalecer la confianza ciudadana en la Administración, resulta esencial someter la actuación de los directivos públicos a un código de conducta que asegure el cumplimiento de los principios de integridad, ejemplaridad, respeto, honestidad, objetividad en la toma de decisiones, profesionalidad, y eficiencia en la gestión». Por lo demás, la unificación de dicho régimen deontológico aportaría claridad y sistemática a la dispersión de principios, derechos y deberes que deben regir la actuación de los directivos públicos, abordada en nuestro país de forma fraccionaria y no siempre unívoca desde diversos bloques normativos: la legislación de trasparencia y buen gobierno, la de empleo público, la de régimen jurídico del sector público y la legislación de altos cargos.

\section{CONCLUSIONES}

El desarrollo de la legislación estatal sobre función pública a partir del mandato constitucional del artículo 103.3 de la CE y del ejercicio de la competencia estatal sobre la legislación básica en la materia (art. $149.1^{\circ} .18^{\mathrm{a}} \mathrm{CE}$ ) ha impuesto una fórmula organizativa tendente a hacer efectiva la dirección política del Gobierno sobre la estructura organizativa de la Administración (art. 97 de la CE) que ha acabado imponiendo la confianza política como criterio determinante en la designación de los titulares de los puestos directivos.

Acaso lo anterior pudiera estar justificado originariamente, en términos históricos, en que los primeros desarrollos constitucionales del estatuto del empleado público no eran ajenos a una cierta desconfianza ante una función pública altamente tecnocrática proveniente del régimen anterior. En todo caso, lo cierto es que hasta la aprobación del EBEP en 2007 existían muy pocos mandatos normativos relativos a la profesionalización de los cargos directivos en la Administración. El EBEP abordó por primera vez la figura del directivo público afirmando ampulosamente en su Exposición de Motivos que «está llamado a constituir en el futuro un factor decisivo de modernización administrativa, puesto que su gestión profesional se somete a criterios de eficacia y eficiencia, responsabilidad y control de resultados en función de los objetivos», pero desarrollando escasamente su régimen jurídico básico (art. 13), que se quedaba al socaire de posteriores desarrollos, tanto estatales como autonómicos.

La legislación estatal vigente regula un sistema de selección y carrera del directivo público inconexa, a partir de cuerpos normativos diversos que atienden a finalidades diferentes y que contienen mandatos excesivamente vagos y principiales, que, además adolecen del desarrollo reglamentario que precisaría la delimitación normativa de un Estatuto básico del directivo público profesional a partir de las escasas previsiones del artículo 13 del TREBEP y que, al cabo, desvirtúan la figura, por su solapamiento con la regulación de los llamados «órganos directivos» y el régimen de los altos cargos, cuyo nombramiento responde antes a criterios políticos y de oportunidad que de aptitud profesional.

El resultado de todo ello es que el modelo directivo en la Administración central no ha conseguido desembarazarse de un modelo gerencial politizado en la designación de cargos directivos y, por otra, de

37 La propuesta de FEDECA es que para garantizar la estabilidad del puesto resulta conveniente fijar un período de permanencia superior al del mandato del órgano que procede a la designación, y toma como referencia para ello el mandato de cinco años, superior a una legislatura. 
un modelo funcionarizado en la exigencia de dicha condición para el acceso a ciertos puestos. Esta disfuncional dualidad de politización de la alta función pública y funcionarización de la política provoca una zona de fricción entre los cargos de designación política y los funcionarios de carrera que deja poco espacio a la existencia de una franja reservada a directivos profesionales.

Por su parte, algunas Comunidades Autónomas, a partir de experiencias de Derecho comparado bien conocidas, han emprendido algunas iniciativas que se desmarcan de la situación de la Administración Central y pretenden abrir un espacio a la función directiva profesional. No obstante, con alguna excepción, se trata de regulaciones poco homogéneas y de diversa intensidad, irregularmente reflejadas en el canon imperante en los países más avanzados de la OCDE y que, han tenido un recorrido más bien escaso; con lo que, al cabo, tampoco puede vislumbrarse -al menos hasta ahora- un modelo autonómico alternativo.

Así, puede afirmarse con carácter general que, en nuestro país, la imparcialidad y la meritocracia que la Constitución exige como garantía del régimen de función pública se ve comprometida por la existencia de un excesivo determinismo del poder político sobre los cuadros profesionales y directivos de la Administración. Siendo éste, sin embargo, el estrato que mayores responsabilidades directivas ha de asumir en orden a la ejecución de los planes y programas de acción y que debería protegerse con garantías de imparcialidad y profesionalidad reforzadas, pese a ser el que sufre el fenómeno de colonización política.

En este orden, la OCDE viene insistiendo en la necesidad de implantar un modelo de dirección pública profesional que responde a parámetros muy precisas de definición, alcance y desarrollo, configurando un verdadero Estatuto del directivo público profesional cuyas claves de implantación hemos tratado de desgranar en torno a las ideas de planificación de plantillas, selección objetiva e imparcial con intervención de una autoridad imparcial y externa al órgano de designación, exigencia del cumplimiento de objetivos a lo largo del mandato y evaluación del rendimiento con efectos retributivos.

\section{REFERENCIAS BIBLIOGRÁFICAS}

ALBAREDA, A.; LOSADA, C. (coords.); LONGO, F.; FÉREZ, M. (2017): El empleo público en España: desafíos para un estado democrático más eficaz. Madrid: Instituto de Estudios Económicos.

BERMEJO VERA, J. (2007): "El personal directivo, ¿nueva tipología de funcionario público?” en AA.VV: El estatuto básico del empleado público y su desarrollo legislativo: curso extraordinario, Zaragoza: Universidad de Zaragoza, 27 y 28 de septiembre de 2007, págs. 195-224. Zaragoza: Universidad de Zaragoza.

FEDECA (2018): Presentación de Fedeca de su propuesta de Estatuto del Directivo Público. Madrid: FEDECA. En prensa. https://fedeca.es/prensa/presentaci\%C3\%B3n-de-fedeca-de-su-propuesta-de-estatuto-del-directivop\%C3\%BAblico.

FOX, B. (1999): “Creating the senior civil service”, Rivista trimestrale di diritto pubblico, núm. 3, págs. 819-827.

GARRIDO FALLA, F. (1970): Tratado de Derecho Administrativo, vol. I. Madrid: Instituto de Estudios Políticos.

JIMENEZ ASENSIO, R. (2009): "La dirección pública profesional: perspectiva comparada y diagnóstico de la situación en España", en JIMENEZ ASENSIO, R.; VILLORIA MENDIETA, M.; PALOMAR OLMEDA, A. (dirs.): La dirección pública profesional en España, pág. 15 y ss. Madrid: Marcial Pons. https://www.marcialpons.es/medial pdf/100857343.pdf.

LAPUENTE, V.; DALHSTROM, C. (2018): Organizando el Leviatan: por qué el equilibrio entre políticos y burócratas mejora los Gobiernos. Bilbao: Universidad de Deusto.

MAESO SECO, L. F. (2011): El personal directivo público en España: su régimen jurídico antes y después del EBEP. Madrid: La Ley.

MINISTERIO DE ASUNTOS ECONÓMICOS Y TRANSFORMACIÓN DIGITAL (2020): ENIA. Estrategia Española en Inteligencia Artificial (España puede). Madrid: Gobierno de España. https://www.lamoncloa.gob.es/presidente/ actividades/Documents/2020/ENIA2B.pdf.

NIETO GARCÍA, A. (2013): "Un primer paso para la reforma de la Administración española", en BAENA DEL ALCÁZAR, M. (coord.): La reforma del Estado y de la Administración española, págs. 207-232. Madrid: INAP.

NUÑEZ MARTÍN, A. (2012): El nuevo directivo público: claves de liderazgo para la gestión pública. Navarra: Ediciones Universidad de Navarra. EUNSA. 1. ${ }^{a}$ ed.

OCDE (2003): Recommendation of the Council on OECD Guidelines for Managing Conflict of Interest in the Public Service [OCDE/LEGAL/0316]. OECD Legal Instruments. París: OCDE. https://legalinstruments.oecd.org/en/ instruments/OECD-LEGAL-0316.

OCDE (1995): Recommendation of the Council on Improving the Quality of Government Regulation [OCDE/ LEGAL/0278]. OECD Legal Instruments. París: OCDE. https://legalinstruments.oecd.org/en/instruments/OECDLEGAL-0278. 
OCDE (2012): Recommendation of the Council on Regulatory Policy and Governance [OCDE/LEGAL/O390]. OECD Legal Instruments. París: OCDE. https://legalinstruments.oecd.org/en/instruments/OECD-LEGAL-0390.

OCDE (2013): Recommendation of the Council on Gender Equality in Education, Employment and Entrepreneurship [OCDE/LEGAL/0398]. OECD Legal Instruments. París: OCDE. https://legalinstruments.oecd.org/en/instruments/ OECD-LEGAL-0398.

OCDE (2015): Recommendation of the Council on Gender Equality in Public Life [OECD/LEGAL/0418]. OECD Legal Instruments. París: OCDE. https://legalinstruments.oecd.org/en/instruments/OECD-LEGAL-0418.

OCDE (2015): Survey on Strategic Human Resources Management in Government, en Directorate for Public Governance. París: OCDE. http://www.oecd.org/gov/survey-on-strategic-human-resources-management-2016. pdf.

OCDE (2016): Engaging Public Employees for a High-Performing Civil Service. OECD Public Governance Reviews. Paris: OECD. https://doi.org/10.1787/9789264267190-en.

OCDE (2017): Skills for a High Performing Civil Service. OECD Public Governance Reviews, París: OCDE. https://doi. org/10.1787/9789264280724-en.

OCDE (2017): Recomendación del Consejo sobre Liderazgo y Capacidad en el Servicio Público. Instrumentos Jurídicos de la OCDE. París: OCDE. http://www.oecd.org/gov/pem/recomendacion-del-consejo-sobre-liderazgo-ycapacidad-en-la-funcon-publica.pdf.

OCDE (2017): Recommendation of the Council on Public Integrity [OECD/LEGAL/0435]. OECD Legal Instruments. París: OCDE. https://legalinstruments.oecd.org/en/instruments/OECD-LEGAL-0435.

OCDE (2020): Public employment and management. Directorate for Public Governance. París: OCDE. http://www. oecd.org/gov/pem/.

PADILLA RUIZ, P. (2018): La evaluación del desempeño en un contexto de mejora de la gestión del empleo público, Tesis Doctoral. Albacete: Universidad de Castilla la Mancha. http://hdl.handle.net/10578/20351.

PALOMAR OLMEDA, A. (2005): "Pautas para el diseño de un estatuto de directivo público para las administraciones convencionales", Revista Vasca de Administración Pública, núm. 72, págs. 195-230. https://dialnet.unirioja.es/ servlet/articulo?codigo=1369187.

PRESIDENCIA DEL GOBIERNO (2020): Plan Español de Recuperación, Transformación y Resiliencia (España puede). Madrid: Gobierno de España. https://www.lamoncloa.gob.es/presidente/actividades/ Documents/2020/07102020_PlanRecuperacion.pdf.

RAMIÓ MATAS, C. (2016): "El Estado en el año 2050: entre la decadencia y el esplendor", Revista del CLAD Reforma y Democracia, núm. 66 , págs. 5-34.

RAMIÓ MATAS, C. (2017): La Administración pública del futuro (Horizonte 2050): instituciones, política, mercado y sociedad de la innovación. Madrid: Tecnos.

RAMIÓ MATAS, C. (2018): “Inteligencia artificial, robótica y modelos de Administración pública”, Revista del CLAD Reforma y Democracia, núm. 72, págs. 5-42.

WEBER, M. (1944): Economía y Sociedad, vol. II, capítulo IX. México: Fondo de Cultura Económica. 